Griep, E.C.M., Noordman, J., Dulmen, A.M. van. Practice nurses mental health provide space topatients to discuss unpleasant emotions. Journal of Psychiatric and Mental Health Nursing: 2016, 23(2), 77-85

\begin{tabular}{|l|l|}
\hline $\begin{array}{l}\text { Postprint } \\
\text { Version }\end{array}$ & 1.0 \\
\hline Journal website & $\frac{\text { http://onlinelibrary.wiley.com/doi/10.1111/ipm.12279/abstract;jsessionid=E9CBOA }}{\text { 85BB079718D4523802997DB8AA.f03t02 }}$ \\
\hline Pubmed link & $\underline{\text { http://www.ncbi.nlm.nih.gov/pubmed/26710237 }}$ \\
\hline DOI & 10.1111/jpm.12279 \\
\hline
\end{tabular}

This is a NIVEL certified Post Print, more info at http://www.nivel.eu

\title{
Practice nurses mental health provide space to patients to discuss unpleasant emotions
}

E. C. M. GRIEP MSC MASTER OF SCIENCE, DOCTOR, RESEARCH COORDINATOR ${ }^{1}$, J. NOORDMAN PHD MASTER OF SCIENCE, DOCTOR, RESEARCH COORDINATOR ${ }^{1, *}$ AND S. VAN DULMEN PHD PROFESSOR, PROFESSOR II ${ }^{1,2,3}$

${ }^{1}$ Master of Science, Doctor, Research Coordinator, NIVEL, Utrecht, The Netherlands ${ }^{2}$ Professor, Radboud University Medical Center, Department of Primary and Community Care, Nijmegen, The Netherlands

${ }^{3}$ Professor II, Faculty of Health Sciences, Buskerud and Vestfold University College, Drammen, Norway

\section{WHAT IS KNOWN ON THE SUBJECT?}

- A core skill of practice nurses' mental health is to recognize and explore patients' unpleasant emotions.

- Patients rarely express their unpleasant emotions directly and spontaneously, but instead give indirect signs that something is worrying them.

WHAT THIS PAPER ADDS TO EXISTING KNOWLEDGE?

- Patients with mild psychosocial and psychological problems provide signs of worrying or express a clear unpleasant emotion in $94 \%$ of consultations with a practice nurse mental health.

- Nurses' responses to patients' signs of worrying or clear unpleasant emotions were mostly characterized by providing space for patients to talk about these emotions, by using minimal responses.

WHAT ARE THE IMPLICATIONS FOR PRACTICE?

- Practice nurses' mental health have passive listening skills, and to a lesser extent, use active listening techniques.

- Accurate emotion detection and the ability to pick out emotional signs during consultations must also be considered as an important skill for health providers

- to improve patient-centred communication.

\footnotetext{
AbStract

Aim: Patients with physical problems are known to express their emotional concerns in an implicit way only. Whether the same counts for patients presenting mental health problems in primary care is unknown. This study aims
} 
Griep, E.C.M., Noordman, J., Dulmen, A.M. van. Practice nurses mental health provide space ton patients to discuss unpleasant emotions. Journal of Psychiatric and Mental Health Nursing: 2016, 23(2), 77-85

to examine how patients with mild psychosocial and psychological complaints express their concerns during consultations with the practice nurse mental health and how practice nurses respond to these expressions. Method: Fifteen practice nurses mental health working in Dutch general practices participated in the study. Their consultations with 116 patients with mild psychosocial or psychological complaints were video recorded. Patients' explicitly expressed emotional concerns and more implicit expressions of underlying emotional problems (cues) as well as nurses' responses to these expressions were rated using the Verona Coding Definition of Emotional Sequences. Results: Almost all consultations contained at least one cue or concern (94\%). Nurses' responses were mostly characterized by providing space for patients to talk about their cue or concern in a non-explicit way (62\%), by using minimal responses $(42 \%)$. Discussion: Practice nurses mental health have passive listening skills, and to a lesser extent, use active listening techniques. However, there are no strict rules which way of responding is the best and patients value responses differently.

\section{INTRODUCTION}

Mental disorders affect hundreds of millions of people worldwide, but most mental disorders remain undetected and untreated (World Health Organisation [WHO] 2008 ). Up to $60 \%$ of people attending primary care have a diagnosable mental disorder. Integrating mental health services into primary care is necessary to ensure that people are directed to the mental health care they need. People can access primary mental health care close to home, thereby avoiding high costs of specialist care and minimizing stigma. Besides, mental and physical health problems are often interwoven. Within primary care both the mental health needs of people with physical complaints and the physical needs of people with mental problems can be addressed. According to the WHO, integrating mental health services into primary care generates good health outcomes and is cost effective (WHO, 2008). Around $10 \%$ of Dutch patients seen in primary care suffer from mental health problems, mostly depression, anxiety and emotional distress (Verhaak et al. 2009). One of the tasks of the general practitioner (GP) within primary care in the Netherlands is to provide mental health care. GP's role as a gatekeeper is of great importance by referring patients to care that is more specialized - when indicated (Van den Brink-Muinen et al. 2003, Van Orden et al. 2009). Since 2008, the practice nurse mental health (PNMH) has been introduced in Dutch general practices, who work under supervision of the GP (Ten Have 2007). The GP can refer patients with mild psychosocial or psychological problems to the PNMH for short-term treatment (Trimbos Institute 2014). The PNMH is responsible for clarifying patients' psychosocial or psychological problems, may provide short treatments and can advise the GP to refer a patient to general or specialized care. This role of the PNMH in the Netherlands is similar to the role of mental health nurses in Australia (Meehan \& Robertson 2015) and the primary care approach to mental health is common in many other countries, like the United Kingdom and Brazil (WHO, 2008). In the Netherlands, the function of the PNMH is rather new and still developing. In $2009,11 \%$ of the general practices worked with a PNMH, while in 2012 this 
Griep, E.C.M., Noordman, J., Dulmen, A.M. van. Practice nurses mental health provide space topatients to discuss unpleasant emotions. Journal of Psychiatric and Mental Health Nursing: 2016, 23(2), 77-85

percentage increased to $47 \%$ (Trimbos Institute 2014). In January 2014, a new niver

structure of the Dutch mental health system was introduced to further restrict rising costs, which resulted from a higher demand on mental health care and limited capacity in secondary care. Therefore, Dutch policy aimed at a substantial shift from secondary mental health care to primary mental health care. Especially, people with mild psychological or psychosocial complaints are supposed to be treated within primary care. Nowadays, more patients with psychosocial or psychological problems are treated by the PNMH within general practice (NZa 2013; Trimbos Institute 2014 ); in $2013,8.6 \%$ of the patients seen by the GP had psychological problems, while in 2014, this percentage increased to $9.9 \%$, which may be due to the implementation of the PNMH (Verhaak et al. 2014). Recent studies described the most common symptoms of patients seen by PNMHs, their activities and referrals and the frequency of contacts with patients (Noordman \& Verhaak 2009, Nijboer 2011, Dozeman \& Van Straten 2012, Verhaak et al. 2012a,b), but so far, no study looked into the process of care provided by PNMHs.

A core skill for PNMHs is to recognize and explore patients' unpleasant or stressful feelings and emotions (i.e. cues and concerns) (Eide et al. 2004). However, patients rarely express their unpleasant feelings and emotions directly and spontaneously, but instead, they give indirect cues that something is worrying them (Butow et al. 2002). It is known that $20-55 \%$ of patients' concerns are adequately identified by the health provider (Heaven \& Maguire 1997, Hill et al. 2003, Farrel et al. 2005, Heaven et al. 2006). Zimmermann's review (2007) showed that it is important to focus on patients' unpleasant or stressful feelings and emotions. Health providers' competence in providing space by using active listening skills is essential to uncover patient's unpleasant emotions (Del Piccolo et al. 2014), and is associated with positive patient care outcomes and greater patient satisfaction (Epstein et al. 2007).

Because of the new mental health structure in the Netherlands and the relatively new function of the PNMH it is unknown to what extent PNMH react to and interact with patients. So far, no research has examined the cues and concerns expressed by patients during consultation with the PNMH. A cue is a verbal or non-verbal sign which may point to an underlying unpleasant emotion that lacks clarity, while a concern refers to a clear and unambiguous expression of an unpleasant current or recent emotion that is explicitly verbalized with or with- out a stated issue of importance. Also, the responses of the PNMH to these cues and concerns have not been studied before.

The following research questions were addressed:

1. How often do patients with mild psychosocial and psy- chological complaints express their cues and concerns during consultations with the PNMH?

2. To what extent and in which way do PNMH respond to these cues and concerns?

\section{METHODS}

\section{Study design}

Observational exploratory study. As this is the first study that investigates the way patients and the PNMH communicate, an exploratory design was considered appropriate. Observing video-recorded consultations is a more valid way to examine the interaction between patients and professionals than self-reports by patients or 
Griep, E.C.M., Noordman, J., Dulmen, A.M. van. Practice nurses mental health provide space topatients to discuss unpleasant emotions. Journal of Psychiatric and Mental Health Nursing: 2016, 23(2), 77-85

PNMH. The video-recorded consultations were coded with the vali- dated Verona Coding Definitions of Emotional Sequences (VR-CoDES-CC) (Zimmermann et al. 2011), see Observation tool.

\section{Ethical consideration}

This study was carried out according to the Dutch privacy legislation. The privacy regulation was approved by the Dutch Data Protection Authority. According to Dutch leg- islation, approval by a medical ethics committee was not required for this observational study. Our research com- plied with the Helsinki Declaration. All subjects gave written informed consent and patient anonymity is preserved.

\section{Participants}

Fifteen PNMH working in Dutch general practices agreed to participate. PNMH were recruited randomly; three PNMH work in the northern part of the Netherlands, one PNMH works in the western part and the remaining eleven PNMH work in the south-eastern part of the Nether- lands. All adult patients with mild psychosocial or psychological problems who were seen by the PNMH on two random days were asked to participate. All PNMH received individual video feedback on their communica- tion skills (Noordman et al. 2011).

\section{Setting}

Consultations between patients with mild psychosocial or psychological problems and PNMH working in Dutch general practices were video recorded. The aim was to record approximately 10 routine consultations per PNMH during 2 random days between March 2014 and December 2014. During these 2 days an unmanned camera was placed in the consultation room. The camera was focussed at the PNMH, so the patients remained out of sight. All patients who had an appointment during these 2 days were informed about the study and asked to participate by a researcher. Approximately 1 week before, the PNMH informed the patients by telephone that a researcher was going to ask the patient to participate in a research on the day of their appointment. The PNMH made clear that patients could go to their appointment independent of partaking in the research.

All participating PNMH and patients were asked to sign a written informed consent form before video record- ing the consultation. PNMH and patients who participated filled out a self-reporting questionnaire on their background characteristics (i.e. patients' and PNMHs' age, gender, education and PNMHs' experience).

Questionnaires used for the PNMH and patients were similar to those used in a previous study (Noordman \& Verhaak 2009). A researcher was present before and after the consultation to ask patients' informed consent and, if necessary, to help patients with the questionnaires. PNMHs and patients were aware that the study focused on the communication skills of PNMH, but they were not aware of the specific attention to cues, concerns and responses. 
Griep, E.C.M., Noordman, J., Dulmen, A.M. van. Practice nurses mental health provide space ton patients to discuss unpleasant emotions. Journal of Psychiatric and Mental Health Nursing: 2016, 23(2), 77-85

\section{Observation tool}

\section{[FIGURE 1]}

All video-recorded consultations were coded using a valid framework for detecting patients' cues and concerns (Eide et al. 2011), the VR-CoDES-CC (Zimmermann et al. 2011). Within this framework, a cue is defined as 'a verbal or non-verbal hint which suggests an underlying unpleas- ant emotion that lacks clarity', while a concern is defined as 'a clear and unambiguous expression of an unpleasant current or recent emotion that is explicitly verbalized with or without a stated issue of importance' (Zimmermann et al. 2011). Cues and concerns can be patient elicited or healthcare provider elicited. The expression of patient-eli- cited cues and concerns is an indicator of patient's initiative or active struggle to direct health provider's attention to specific worries. Provider-elicited cues and concerns are an indicator of the space given to patients to explicate their concerns without patients having to take initiatives.

The responses of the PNMH on expressed cues and concerns by patients were coded using the VR-CoDES-P (Del Piccolo et al. 2011). Only immediate responses to cues and concerns were coded, which refer to the first reaction after a cue or concern. Responses were coded according to two major conceptual factors: explicitness and space provision for further disclosure of the cue or concern (Fig. 1). A response can be coded as 'explicit' or as 'non-explicit'. An explicit response is any response that specifically mentions either the content/topic or the emo- tion in the cue or concern, or both. A non-explicit response does not explicitly mention either the content or the emotion of the cue or concern. After coding explicit or non-explicit, the response can be coded as 'providing space' or as 'reducing space'. Providing space refers to any intervention that gives space for further disclosure of the cue or concern expressed by the patient; reducing space is any response or intervention that reduces the space for or blocks further disclosure about the cue or concern expressed by the patient. Definitions and examples of the response categories can be found in Del Piccolo et al. (2011). As recommended by one of the authors of the VR-CoDES (i.e. Del Piccolo), when attending a VR-CoDES-training day, we did not code the psychosocial or psychological complaint of the patient per se as a cue or concern. VR-CoDES has been used before rating cues, concerns and responses in consultations of psychiatrists (Del Pic- colo et al. 2012), dentists (Zhou et al. 2014), nurses in oncology (Heyn et al. 2012, Finset et al. 2013, Mellblom et al. 2014), nurses in paediatric oncology (Vatne et al. 2010), physicians in primary care (De Maesschalck et al. 2011, Schouten \& Schinkel 2014) and medical students (Mazzi et al. 2013). All the studies reported a moderate to good inter-rater reliability. For the present study, the VR-CoDES coding scheme was incorporated into Observer software (Noldus et al. 2000) making it possible to rate the consultations directly from video.

\section{Reliability observations}

All video-recorded consultations were coded by one observer (EG), who attended a VR-CoDES-training day of the authors of this coding system. The mean duration of the video-recorded consultations was $31.5 \mathrm{~min}$ (range $=10-62 \mathrm{~min}$ ). Coding the video-recorded consultations took approximately twice the duration of the recording; videos were watched one time. Reliability was tested using the intra-class correlation coefficient (ICC). Eleven consultations were coded by a second observer. The mean 
Griep, E.C.M., Noordman, J., Dulmen, A.M. van. Practice nurses mental health provide space topatients to discuss unpleasant emotions. Journal of Psychiatric and Mental Health Nursing: 2016, 23(2), 77-85

intra-class correlation of patient expressed cues and concerns was 0.97 . The mean intra-class correlation of PNMHs' responses was 0.86 (range $=0.47-1.00$ ). The interrater reliability of the VR-CoDES-CC and VR-CoDES-P between the two observers was found to be satisfactory to good (Sim \& Wright 2005, Fletcher et al. 2011).

\section{Statistical analysis}

Background characteristics of the PNMH and patients (i.e. patients' and PNMHs' age, gender, education and PNMHs' experience) were described using descriptive sta- tistical techniques (e.g. mean, SD). Descriptive statistics were also used to analyse frequencies of patients' cues and concerns and PNMHs' responses on patients' cues and concerns. Data were analysed using Stata 11 (Stata [com- puter program]. Version 12. Copyright 2009, by Stata- Corp LP, 4905 Lakeway Drive, College Station, TX 77845 USA. www.stata.com.), except for the ICCs that were calculated using SPSS (version 18.0; PASW Statistics USA, Westlands Road, Quarry Bay, Hong Kong, China).

\section{[TABLE 1]}

\section{RESULTS}

\section{Characteristics of PNMHs and patients}

Table 1 describes the characteristics of the PNMH and patients. Fifteen PNMH participated in this study. A total of 172 patients were asked for participating in this study. Patients' non-response rate was $31 \%$. The reasons for non-participation were 'feeling uncomfortable with the camera', 'feeling uncomfortable because it was an intake- consultation' and privacy reasons. The total number of patients who agreed to have their consultation video recorded was 119 during the 117 consultations [i.e. during two consultations two patients (as couples) were pre- sent]. Because of technical failure one consultation was not recorded, resulting in 116 consultations. Per PN men- tal health between 4 and 12 (mean of 7.7) recordings were made. Mean duration of the consultations was $31.5 \mathrm{~min}$ (range $=10-62 \mathrm{~min})$.

\section{Expression of cues and concerns by patients}

\section{[TABLE 2]}

In $109(94 \%)$ of the 116 consultations, cues or concerns were identified. In the remaining $7(6 \%)$ consultations, no cues or concerns were observed. In the 116 consultations, a total of 598 cues and concerns were expressed (see Table 2). Patients expressed on average 3.6 cues and 1.5 concerns per consultation. The initiative of expressing cues and concerns was more frequently taken by the patient (66\%) than by the health provider (34\%). 
Griep, E.C.M., Noordman, J., Dulmen, A.M. van. Practice nurses mental health provide space topatients to discuss unpleasant emotions. Journal of Psychiatric and Mental Health Nursing: 2016, 23(2), 77-85

\section{PNMHs responses to cues and concerns}

PNMHs responses are categorized in four different cate- gories, as shown in Fig. 1.

Table 3 shows the frequencies of the different categories and some examples.

PNMHs responses to cues and concerns were mostly characterized by providing space for patients to talk about their cue or concern (86\%), mainly in a non-explicit way $(62 \%)$. Giv- ing minimal responses ('back-channels') was the most frequent way $(42 \%)$ for PNMHs to respond to cues and concerns. 'Back-channel' is any response that provides space for the patient to say more or that encourages fur- ther disclosure, through using a minimal prompt, or word, but not a full statement. For example: Mmm, Yes, Right, Ok. Thereby, the PNMHs gave the patient an opportunity to talk more about the emotion that they had disclosed. There were 86 responses $(14 \%)$ that reduced the space for further disclosure of emotion.

\section{DISCUSSION}

\section{[TABLE 3]}

The aim of this study was to explore how often patients with mild psychosocial and psychological complaints express cues and concerns during consultations with the PNMH and to what extent and in which way PNMHs respond to these cues and concerns. This study shows that patients with mild psychosocial and psychological prob- lems express both cues and concerns in consultation with a PNMH. Almost all consultations (94\%) contained at least one cue or concern, which is consistent with a study with psychiatrists (Del Piccolo et al. 2012). Similar studies in settings different from mental health (De Maesschalck et al. 2011, Mjaaland et al. 2011, Mellblom et al. 2014) have reported percentages between $61 \%$ and $50 \%$ of consultations in which patients' expressed cues and concerns. The total number of consultations with cues and concerns and the total number of expressed cues and concerns per consultation was high in this study, compared to similar studies in different settings (Mjaaland et al. 2011, Finset et al. 2013). These differences can be explained by the dif- ferent settings and the different origin of patients' com- plaints. It is known that cues and concerns are relatively rare phenomena in medical consultations (Mjaaland et al. 2011), while cues and concerns are more present in set- tings with patients with mild psychosocial and psychological complaints (Zimmermann et al. 2007). Del Piccolo et al. (2014) found that type and frequency of expressed emotion vary with patient diagnosis and that patients with mood disorders talked more explicitly and more often about their emotions, which is consistent with our results. In agreement with earlier studies (Vatne et al. 2010, Mjaaland et al. 2011, Zhou et al. 2014), cues are far more frequent than concerns. Compared to Finset et al. (2013), who found an average of 2.4 cues and 0.6 concerns per consultation in cancer care, the patients in our study expressed more cues and concerns; 3.3 cues and 1.4 concerns per consultation. Previous studies examined cues and concerns in consultations with health providers in medical settings and showed a relatively lower number of concerns, varying between $9 \%$ and 20\%, compared to 29\% in our study (Mjaaland et al. 2011, Finset et al. 2013, Zhou et al. 2014). The differences in frequencies of cues and concerns in previous studies cannot entirely be attributed to the different settings of consultation. Also other factors, like the length of consultations, age, gender and 
Griep, E.C.M., Noordman, J., Dulmen, A.M. van. Practice nurses mental health provide space ton patients to discuss unpleasant emotions. Journal of Psychiatric and Mental Health Nursing: 2016, 23(2), 77-85

ethnicity of the patient and provider, and different statistical analyses are likely to affect the results (Zimmer- mann et al. 2007).

During consultations, attention to emotions that are expressed by patients have important implications for the diagnostic process, particularly in mental health settings (Del Piccolo et al. 2012). Therefore, it is important to know how the cues and concerns are expressed, if they are patient elicited or provider elicited. The initiative to express cues and concerns was more frequently taken by the patient than by the health provider. Levinson et al. (2000) also found that patient-initiated cues were approximately three times more frequent than doctor-initiated cues in consultation with a GP.

It is also relevant how PNMHs respond to patients' emotions (Del Piccolo et al. 2012). Regarding the immedi- ate responses given by the PNMHs, providing space was most common and contained almost $90 \%$ of all responses. Most of the providing space responses were non-explicit, using minimal prompts or words (back-channel), acknowl- edgements and active invitation to seek further disclosure or new information, without making explicit reference to the emotion that was expressed by the patient. Just over $10 \%$ of the responses were coded as reducing space, which does not mean that the response of the PNMH blocks the patient. In half of the reducing space responses the PNMH ignored the cue or concern, but in the other half information or advice was given for possible solutions for the emo- tion the patient had expressed.

The most common response was back-channel (42\%), a minimal prompt or word, giving the patient space to talk more about the emotion. This finding was also presented by Rimondini et al. (2006), who showed that psychiatrists are good passive listeners (by responding with back-channel) but less competent in using active listening techniques (by providing space in an explicit response). Another study in a psychiatric setting showed that physi- cians preferred to respond in a passive way by listening and giving explicit back-channel responses and often hesi- tated to respond actively (McCabe et al. 2002). This is consistent with our finding that the PNMHs in our study mainly responded in a non-explicit way (73\%). PNMHs have passive listening skills, but to a lesser extent use active listening techniques. There are no strict rules which way of responding is the best. Some types of health provi- der responses are differently valued by patients (Mazzi et al. 2013). It is known that health providers' competence in providing space by using active listening skills is essential to uncover patient's emotions (Del Piccolo et al. 2014). Providing space to patients who show signs of distress is universally appreciated by all patients (Mazzi et al. 2013), but every patient needs a different response. Zim- mermann et al. (2003) showed that silence, a non-explicit providing space response, on the part of the health provi- der may promote the expression of cues and concerns. In some situations, a non-explicit response to a patient cue of concern may be more adequate than an explicit response, depending on the diagnosis, type of patient and expectation of the patient (Del Piccolo et al. 2014).

Helping patients to verbalize their feelings by a good detection, identification and response, generates greater patient satisfaction (Epstein et al. 2007). However, Butow et al. (2002) showed that patient satisfaction and state anxiety turned out to be unaffected by physicians' reac- tion to informational and emotional cues. This can be explained by the fact that Epstein et al. (2007) and Butow et al. (2002) used different criteria. Butow et al. (2002) used criteria like appropriate and inappropriate 
Griep, E.C.M., Noordman, J., Dulmen, A.M. van. Practice nurses mental health provide space ton patients to discuss unpleasant emotions. Journal of Psychiatric and Mental Health Nursing: 2016, 23(2), 77-85

responses, postponing, ignoring and interrupting, while Epstein et al. (2007) used a more extensive protocol with 10 categories similar to the VR-CoDES-P. In the present study, patients' outcome measures were not included.

This study has focused on responses to negative emotions, cues and concerns. Health providers must detect the cue or concern before they can identify the type of emotion and respond (Blanch-Hartigan 2013). Accurate emotion detection and the ability to pick out signs of emotion during consultations must also be con- sidered as an important skill for health providers within mental health to improve patient-centred communica- tion. An active attitude of the mental health nurse, by using exploration, acknowledgement and empathic statements, gives patients the opportunity to express their emotions and, as a consequence, improve the diagnostic and therapeutic process.

The results of this study give a first insight into the interaction between PNMHs and patients. The number of PNMHs is expected continue to rise over the next years. Further research is needed to get more insight into the communication skills of the PNMH. This can contribute to the development of a more uniform PNMH function and competence profile. In January 2015, a new function profile of the PNMH was pub- lished, but implementation in practice need further research (LHV 2014). It is also recommended to inves- tigate patient outcomes and patient experiences, which can contribute to the quality of this new profession. The insight into current mental health nursing practice provided by this study is especially relevant given its recent introduction in primary care in the Netherlands. The new role of a mental health practice nurse needs to become further developed in upcoming years. Our study results provide a baseline measure of nurses' communication performance and can as such contribute to establish mental health practice nurses' task profiles and to recognize additional training needs. As in other countries, the role of the mental health practice nurse is rather new and studies into current practices have yet to be initiated, this study may help to move this field of health care a step further, in the Netherlands and beyond.

\section{Strengths and limitations}

This observational study is based on a collection of rou- tine daily consultations between PNMHs and patients. The VR-CoDES is a valid framework to capture cues and concerns experienced by patients (Eide et al. 2011) and may have potential implications for clinical practice when linked to patient outcomes such as satisfaction or treatment adherence. This is the first study to investigate the way patients and the PNMH in the Netherlands com- municate. Some limitations should also be mentioned. It is difficult to compare the present study with previous studies because of the different settings (e.g. different patient groups, professionals, countries).

Second, this study does not include patient outcomes. However, this was not the aim of the study. Third, a limitation of VR-CoDES is that cues and concerns of the patient are leading and therefore efforts of the PNMH to uncover a negative emotion of the patient could be missed when the patient does not express a cue or concern. Furthermore, VR-CODES focuses on negative emotions of patients, so positive emotions are not coded. Previous studies have shown that attention to positive emotions can be a powerful therapeutic agent and that both positive and negative emotions are necessary to the successful comple- tion of therapy (Fitzpatrick \& Stalikas 2008). 
Griep, E.C.M., Noordman, J., Dulmen, A.M. van. Practice nurses mental health provide space ton patients to discuss unpleasant emotions. Journal of Psychiatric and Mental Health Nursing: 2016, 23(2), 77-85

Finally, this is a small-scale exploratory study. Future research among a larger population is necessary to further explore the findings in the present study.

\section{REFERENCES}

Blanch-Hartigan D. (2013) Patient satisfaction with physician errors in detecting and identifying patient emotion cues. Patient Education and Counseling 93, 56-62.

Butow P.N., Brown R.F., Cogar S., et al. (2002) Oncologists' reaction to cancer patients' verbal cues. Psycho-Oncology 11, 47-58.

De Maesschalck S., Deveugele M. \& Willems S. (2011) Language, culture and emotions: explor- ing ethnic minority patients' emotional expres- sion in primary healthcare consultations. Patient Education and Counseling 84, 406-412.

Del Piccolo L., de Haes H., Heaven C., et al. (2011) Development of the Verona coding definitions of emotional sequences to code health providers' responses (VR-CoDES-P) to patient cues and concern. Patient Education and Counseling 82, 149-155.

Del Piccolo L., Mazzi M.A., Goss C., et al. (2012) How emotions emerge and are dealt with in first diagnostic consultations in psychi- atry. Patient Education and Counseling 88, 29 35.

Del Piccolo L., Danzi O., Fattori N., et al. (2014) How psychiatrist's communication skills and patient's diagnosis affect emotion disclosure during first diagnostic consultations. Patient Education and Counseling 96, 151-158.

Dozeman E. \& Van Straten A. (2012) De praktijkondersteuner GGZ in Amsterdam: op weg naar een sterke Basis GGZ [The Practice Nurse Mental Health in Amsterdam: Towards a Strong Basic Mental Healthcare]. Vrije Universiteit, Amsterdam.

Eide H., Quera V., Graugaard P., et al. (2004) Physician-patient dialogue surrounding patients' expression of concern: applying sequence analysis to RIAS. Social Science \& Medicine 59, 145-155.

Eide H., Eide T., Rustøen T., et al. (2011) Patient validation of cues and concerns identified according to Verona coding definitions of emo- tional sequences (VR-CoDES): a videoand interview-based approach. Patient Education and Counseling 82, 156-162.

Epstein R.M., Hadee T., Carrol J., et al. (2007) Could this be something serious? Reassurance, uncertainty, and empathy in response to patients' expression of worry. Journal of Gen- eral Internal Medicine 22, 1731-1739.

Farrel C., Heaven C., Beaver K., et al. (2005) Identifying the concerns of women undergoing chemotherapy. Patient Education and Counsel- ing 56, 72-77.

Finset A., Heyn L. \& Ruland C. (2013) Patterns in clinicians' responses to patient emotion in cancer care. Patient Education and Counseling 93, 80-85.

Fitzpatrick M.R. \& Stalikas A. (2008) Integrating positive emotions into theory, research, and practice: a new challenge for psychotherapy. Journal of Psychotherapy Integration 18, $248-258$.

Fletcher I., Mazzi M. \& Neubling M. (2011) When coders are reliable: the application of three measures to assess inter-rater reliability/ agreement with doctor-patient communication data coded with the VR-CoDES. Patient Edu- cation and Counseling 82, 341-345.

Heaven C.M. \& Maguire P. (1997) Disclosure of concerns by hospice patients and their identifi- cation by nurses. Palliative Medicine 11, 283- 290.

Heaven C., Glegg J. \& Maguire P. (2006) Trans- fer of communication skill training from work- shop to workplace: the impact of clinical supervision. Patient Education and Counseling 60, 313-325.

Heyn L., Ruland C.M. \& Finset A. (2012) Effects of an interactive tailored patient assessment tool on eliciting and responding to cancer patients' cue and concern in clinical consultations with physicians and nurses. Patient Edu- cation and Counseling 86, 158-165.

Hill K.M., Amir Z., Muers M.F., et al. (2003) Do newly diagnosed lung cancer patients feel their concerns are being met? European Journal of Cancer Care 12, 35-45.

Levinson W., Horawara-Bhat R. \& Lamb J. (2000) A study of patient clues and physician responses in primary care and surgical settings. Journal American Medical Associations 284, 1021-1027. 
Griep, E.C.M., Noordman, J., Dulmen, A.M. van. Practice nurses mental health provide space ton patients to discuss unpleasant emotions. Journal of Psychiatric and Mental Health Nursing: 2016, 23(2), 77-85

LHV (2014). Het functie- en competentieprofiel praktijkondersteuner huisartsenzorg GGZ [The function- and competence profile practice nurse mental health]. Available at: https://www.Ihv. nl/actueel/nieuws/nieuw-functie-en-competentie profiel-voorpraktijkondersteuner-ggz (accessed 2 January 2015).

Mazzi M.A., Bensing J., Rimondini M., et al. (2013) How do lay people assess the quality of physicians' communicative responses to patients' emotional cues and concerns? An international multicenter study based on video- taped medical consultations. Patient Education and Counseling 90, 347-353.

McCabe R., Heath C., Burns T., et al. (2002) Engagement of patients with psychosis in the con- sultation: conversation analytic study. British Medical Journal 325, 1148-1151.

Meehan T. \& Robertson S. (2015) Impact of mental health nurse incentive programme on patient functioning. International Journal of Mental Health Nursing 24, 75-81.

Mellblom A.V., Finset A., Korsvold L., et al. (2014) Emotional concerns in follow-up consultations between paediatric oncologists and adolescent survivors: a video-based observa- tional study. Psycho-Oncology 23, 1365-1372.

Mjaaland T.A., Finset A., Jensen B.A., et al. (2011) Patients' negative emotional cues and concerns in hospital consultations: a video- based observational study. Patient Education and Counseling 85, 356-362.

Nijboer W. (2011) Enquete POH-GGZ West- Overijssel [Questionnaire Practice Nurse Mental Health West-Overijssel]. ProGez, Zwolle.

Noldus L.P.J.J., Trienes R.J.H., Hendriksen A.H.M., et al. (2000) The Observer Video-Pro: new software for the collection, management, and presentation of time-structured data from videotapes and digital media files. Behavior Research Methods, Instruments and Computers 32, 197-206.

Noordman J. \& Verhaak P.F.M. (2009) Psychische gezondheid in de eerste lijn. De inzet van con- sulenten geestelijke gezondheid in Gezondheids- centrum West, bij pati€enten met psychische of sociale klachten [Mental Health in Primary Care. Mental Health Counselors in Healthcare Center West, for Patients with Psychological or Social Problems]. NIVEL, Utrecht.

Noordman J., Verhaak P. \& van Dulmen S. (2011) Web-enabled video-feedback: a method to reflect on the communication skills of expe- rienced physicians. Patient Education and Counseling 82, 335-340.

NZa (2013) Advies bekostiging POH-GGZ [Advise Financing Practice Nurse Mental Health] Nederlandse Zorgautoriteit, Utrecht.

Rimondini M., Del Piccolo L., Goss C., et al. (2006) Communication skills in psychiatry residents. How do they handle patient concerns ? Psychotherapy and Psychosomatics 75, 161-169.

Schouten B.C. \& Schinkel S. (2014) Turkish migrant GP patients' expression of emotional cues and concerns in encounters with and with- out informal interpreters. Patient Education and Counseling 97, 23-29.

Sim J. \& Wright C.C. (2005) The Kappa statistic in reliability studies: use, interpretation and sample size requirements. Physical Therapy $85,257-268$.

Ten Have J.J.I.M. (2007) Praktijkondersteuning GGZ in de eerste lijn. Een eerste beschrijving van de functie praktijkondersteuning GGZ in de eerste lijn [Practice Nurses Mental Health in Primary Care. A Description of the Function Practice Nurse Mental Health in Primary Care]. Landelijke

Vereniging Georganiseerde eerste lijn, Utrecht. Trimbos Institute (2014) Trendrapportage GGZ,

themarapport. Versterking van de GGZ in de

huisartspraktijk [Mental Health Report. Strengthening of Mental Health in General Practice]. Trimbos-institute, Utrecht, The Netherlands.

Van den Brink-Muinen A., Verhaak P.F.M., Bens- ing J., et al. (2003) Communication in general practice: differences between European coun- tries. Family Practice 20, 478-485.

Van Orden M., Hoencamp E., Haffmans J., et al. (2009) Collaborative mental health care versus care as usual in a primary care setting: a ran- domized controlled trial. Psychiatric Services 60, 74-79. 
Griep, E.C.M., Noordman, J., Dulmen, A.M. van. Practice nurses mental health provide space topatients to discuss unpleasant emotions. Journal of Psychiatric and Mental Health Nursing:

2016, 23(2), 77-85

Vatne T.M., Finset A., Ornes K., et al. (2010) Application of the Verona coding definitions of emotional sequences (VR-CoDES) on a pedi- atric data set. Patient Education and Counsel- ing 80, 399-404.

Verhaak P.F.M., Prins M.A., Spreeuwenberg P., et al. (2009) Receiving treatment for common mental disorders. General Hospital Psychiatry 31, 46-55.

Verhaak P.F.M., Van Dijk C.E., Nuijen N., et al. (2012a) Mental health care as delivered by Dutch general practitioners between 2004 and 2008. Scandinavian Journal of Primary Health Care 30, 156-162.

Verhaak P.F.M., Van der Zee D., Conradi M., et al. (2012b) Praktijkondersteuner-ggz maakt verwachting waar [Practice nurse mental health realizes expectations]. Tijdschrift voor Prakti- jkondersteuning 2, 41-46.

Verhaak P., Magn'ee T., Hooiveld M., et al. (2014) Gevolgen invoering Basis GGZ voor de psychische en sociale hulpvraag in de huisartspraktijk [Effects of Introducing Basic Mental Health for Psychological and Social Demand for Care in General Practice]. NIVEL, Utrecht. WHO (2008) Integrating Mental Health into Primary Care- a Global Perspective. World Health Organization, Geneva, Switzerland.

Zhou Y., Black R., Freeman R., et al. (2014) Applying the Verona coding definitions of emotional sequences (VR-CoDES) in the den- tal context involving patients with complex communication needs: an exploratory study. Patient Education and Counseling 97, 180187.

Zimmermann C., Del Piccolo L. \& Mazzi M.A. (2003) Patient cues and medical interviewing in general practice: examples of the application of sequential analysis. Epidemiologia e psichiatria sociale $12,115-123$.

Zimmermann C., Del Piccolo L. \& Finset A. (2007) Cues and concerns by patients in medical consultations: a literature review. Psycho- logical Bulletin 133, 438-463.

Zimmermann C., Del Piccolo L., Bensing J., et al. (2011) Coding patient cues and concerns in medical consultations: the Verona coding definitions of emotional sequences (VRCoDES). Patient Education and Counseling 82, 141-148.

\section{TABLES AND FIGURES}

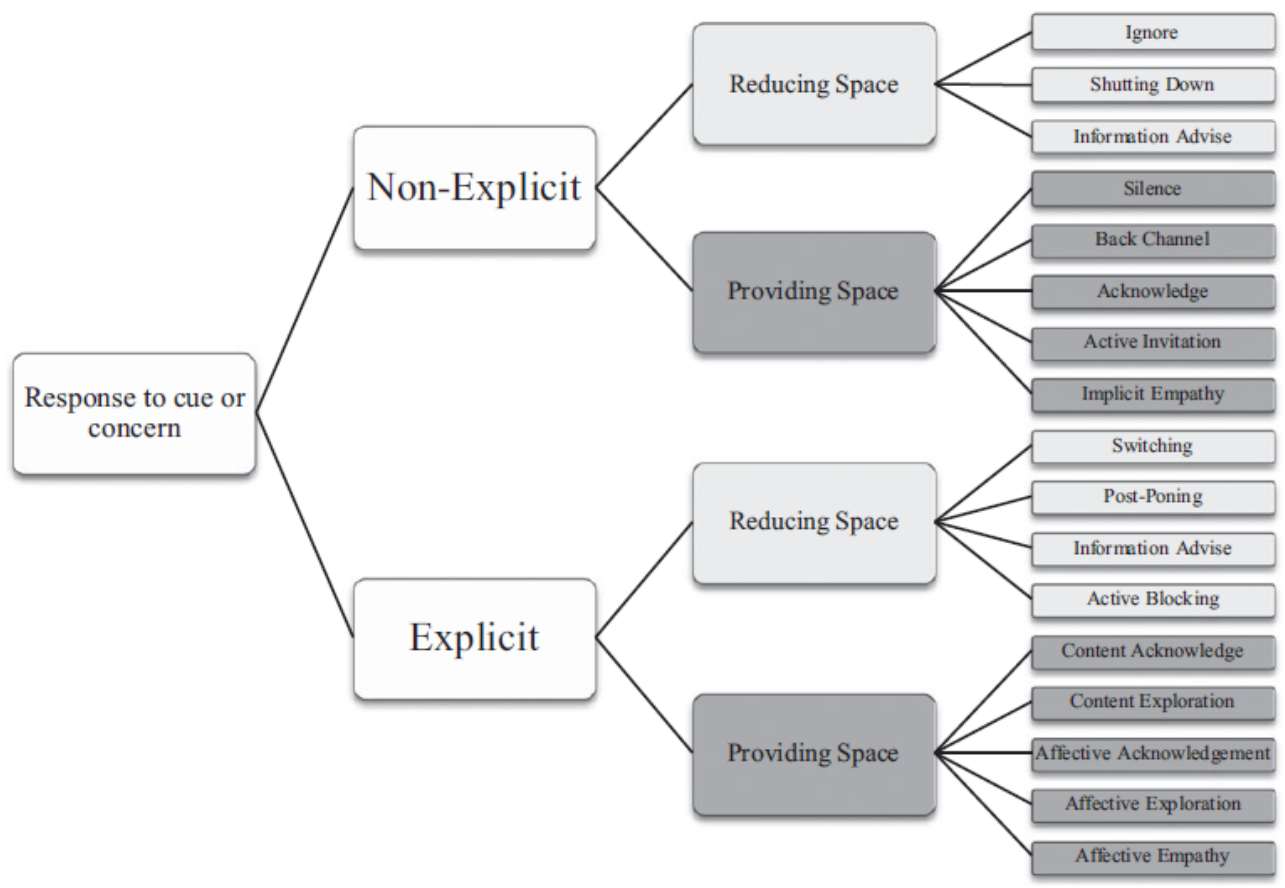

Figure 1

Categories of responses as described in the Verona Coding Definitions of Emotional Sequences to code health providers' responses (Del Piccolo et al. 2011). 
Griep, E.C.M., Noordman, J., Dulmen, A.M. van. Practice nurses mental health provide space topatients to discuss unpleasant emotions. Journal of Psychiatric and Mental Health Nursing: 2016, 23(2), 77-85

Table 1

Characteristics of practice nurse mental health (PNMHs) $(n=15)$ and patients $\left(n=114^{1}\right)$

\begin{tabular}{llc}
\hline Characteristics & PNMHs & Patients \\
\hline Female (\%) & 80 & 62 \\
Male (\%) & 20 & 38 \\
Mean age in years (range) & $47(30-61)$ & $44(18-87)^{2}$ \\
Experience in years (range) & $1.9(0.4-6)$ & - \\
Education (\%) & & \\
$\quad$ Higher vocational education & 73 & \\
University & 27 & \\
Education ${ }^{3}(\%)$ & & 17 \\
No/low & & 39 \\
Middle & & 44 \\
High & & \\
\hline
\end{tabular}

${ }^{1}$ The characteristics of the patients $(n=4)$ who attended the same consultation (as a couple) are not included.

${ }^{2} n=113,3$ missing.

${ }^{3} n=108,8$ missing.

Table 2

Frequencies of the expressed cues and concerns

\begin{tabular}{ll}
\hline & Frequencies $N(\%)$ \\
\hline Total cues and concerns & 598 \\
Patient cues & $423(71)$ \\
Patient concerns & $175(29)$ \\
\hline
\end{tabular}


Griep, E.C.M., Noordman, J., Dulmen, A.M. van. Practice nurses mental health provide space topatients to discuss unpleasant emotions. Journal of Psychiatric and Mental Health Nursing:

2016, 23(2), 77-85

Table 3

Practice nurse mental health responses to patient cues, concerns and examples

\begin{tabular}{|c|c|c|}
\hline $\begin{array}{l}\text { Category } \\
\text { of responses }\end{array}$ & Frequencies, $N(\%)$ & Examples \\
\hline Non-explicit reducing space (NR) & $66(11)$ & \\
\hline \multirow[t]{2}{*}{ Ignore } & $53(9)$ & Cue: 'I don't have energy for it' \\
\hline & & Response: 'Another question, how do you sleep?' [1-1] \\
\hline Shutting down & - & - \\
\hline \multirow[t]{2}{*}{ Information advise } & $13(2)$ & Cue: 'I can't manage it' \\
\hline & & Response: 'What you're doing is good, keep doing that' [7-1] \\
\hline Non-explicit providing space (NP) & $371(62)$ & \\
\hline \multirow[t]{2}{*}{ Silence } & $9(2)$ & Cue: 'That is difficult' \\
\hline & & Response: '...........' [8-1] \\
\hline \multirow[t]{2}{*}{ Back-channel } & $248(42)$ & Cue: 'That is what bothers me' \\
\hline & & Response: 'Hmm’ [6-1] \\
\hline \multirow[t]{2}{*}{ Acknowledge } & $34(6)$ & Cue: 'It is so difficult' \\
\hline & & Response: 'I see..' [3-1] \\
\hline \multirow[t]{2}{*}{ Active invitation } & $61(10)$ & Concern: 'I am worried about it' \\
\hline & & Response: 'More than the last time we spoke to each other?' [4-1] \\
\hline \multirow[t]{2}{*}{ Implicit empathy } & $19(3)$ & Cue: 'It is not going well' \\
\hline & & Response: ‘O, I'm sorry' [4-2] \\
\hline Explicit reducing space (ER) & $20(3)$ & \\
\hline \multirow[t]{2}{*}{ Switching } & $3(0.5)$ & Cue: 'I don't trust it' \\
\hline & & Response: 'The last time you were more positive' [1-2] \\
\hline \multirow[t]{2}{*}{ Postponing } & $1(0.2)$ & Concern: 'It is so difficult'- \\
\hline & & Response: 'We talk about that later' [10-1] \\
\hline \multirow[t]{2}{*}{ Information advise } & $14(2)$ & Concern: 'I am so nervous for this consult' \\
\hline & & Response: 'You don't have to be nervous' [2-1] \\
\hline \multirow[t]{2}{*}{ Active blocking } & $2(0.3)$ & Cue: 'I hate myself now' \\
\hline & & Response: 'Oh, that's normal' [9-1] \\
\hline Explicit providing space (EP) & $141(24)$ & \\
\hline Content acknowledge & - & - \\
\hline Content exploration & - & - \\
\hline \multirow[t]{2}{*}{ Affective acknowledge } & $68(11)$ & Concern: 'It is difficult for me' \\
\hline & & Response: 'It is difficult' [5-1] \\
\hline \multirow[t]{2}{*}{ Affective exploration } & $64(11)$ & Concern: 'It is difficult for me' \\
\hline & & Response: 'Why is it difficult for you?'[6-2] \\
\hline \multirow[t]{2}{*}{ Affective empathy } & $9(2)$ & Cue: 'That is so difficult for me' \\
\hline & & Response: 'I understand that it is difficult for you' [2-2] \\
\hline
\end{tabular}

